Research article

\title{
Tumour Fas ligand : Fas ratio greater than 1 is an independent marker of relative resistance to tamoxifen therapy in hormone receptor positive breast cancer
}

\author{
Toralf Reimer ${ }^{1}$, Dirk Koczan², Heiner Müller ${ }^{1}$, Klaus Friese ${ }^{1}$, Hans-Jürgen Thiesen ${ }^{2}$ and Bernd Gerber ${ }^{1}$ \\ 1Department of Obstetrics \& Gynaecology and 2Institute of Immunology, University of Rostock, Faculty of Medicine, Rostock, Germany
}

Correspondence: Toralf Reimer, MD, Department of Obstetrics \& Gynaecology University of Rostock, POB 1008 88, D-18055 Rostock, Germany. Tel: +49 (0)381 494 8101; fax: +49 (0)381 494 8102; e-mail: toralf.reimer@med.uni-rostock.de

Received: 14 April 2002

Revisions requested: 8 May 2002

Revisions received: 24 May 2002

Accepted: 28 May 2002

Published: 21 June 2002
Breast Cancer Res 2002, 4:R9

(C) 2002 Reimer et al., licensee BioMed Central Ltd

(Print ISSN 1465-5411; Online ISSN 1465-542X)

\begin{abstract}
Background: The objective of the present study was to examine the prognostic and predictive significance of the apoptosis-related marker Fas ligand (FasL) : Fas ratio in breast cancer.

Methods: Tumour biopsies from 215 primary invasive breast cancer patients were examined for the expression of FasL and Fas mRNA transcripts by quantitative real-time RT-PCR. Their prognostic and predictive impact on patient survival was determined in univariate and multivariate survival analyses.

Results: Using a cutoff value of 1, a FasL:Fas ratio greater than 1 was found to have significant prognostic value for disease-free survival among the total population (median follow up 54 months). It was associated with a significantly decreased disease-free survival $(P=0.022)$ and with a tendency toward increased mortality $(P=0.14)$ in univariate analysis. Hormone receptor positive women exclusively treated with tamoxifen $(n=86)$ and with a FasL: Fas ratio greater than 1 had a significantly decreased disease-free survival $(P=0.008)$ and overall survival $(P=0.03)$ in univariate Kaplan-Meier analysis. Furthermore, tumour size and FasL: Fas ratio were of independent predictive significance in the multivariate model for disease-free and overall survival in that subgroup. Among postmenopausal patients $(n=148)$ both of those factors retained independent prognostic significance in the multivariate model for disease-free survival. In contrast, FasL: Fas ratio had no significant predictive value in patients exclusively treated with chemotherapy.

Conclusion: The data presented indicate that FasL: Fas ratio may be useful not only as a prognostic factor but also as a predictive factor for projecting response to the antioestrogen tamoxifen. The results strongly support a correlation between FasL: Fas ratio greater than 1 and lack of efficacy of tamoxifen in hormone receptor positive patients.
\end{abstract}

Keywords: apoptosis, breast cancer, Fas ligand, predictive factor, tamoxifen

\section{Introduction}

The Fas receptor (CD95/APO-1) is a widely expressed glycosylated cell surface molecule of approximately $45-52 \mathrm{kDa}$. It is a type I transmembrane receptor and can also occur in several soluble forms. Under physiological conditions Fas-mediated apoptosis is triggered by Fas ligand (FasL/CD95L), the natural ligand of the receptor. FasL was shown to be a tumour necrosis factor related type II transmembrane molecule, and its expression is more restricted than that of Fas [1]. 
FasL is predominantly detected in activated $\mathrm{T}$ cells and activated natural killer cells, but it is also found on some macrophages/monocytes and on cells of immune privileged tissues [2]. Although there is evidence that some cancers express FasL on their cell surface, creating an immune privileged site $[3,4]$, a number of laboratories have failed to confirm these observations $[5,6]$. These findings, in addition to a report that tumours transfected with genes that express FasL (which was originally predicted to accelerate engraftment) were unexpectedly rejected [7], have confounded interpretation of the earlier studies and the role of FasL in immune recognition of malignancies [8-10].

In invasive breast carcinomas the expressions of Fas and FasL appeared to be inversely related [11]. A significant association was observed between FasL and the presence of metastatic lymph nodes and larger tumour size, whereas Fas expression was correlated with node-negative status and smaller tumour size [12]. Furthermore, high FasL mRNA and protein expression appears to be positively correlated with histological grading $[13,14]$, suggesting that a neoplastic Fas-negative/FasL-positive phenotype may be linked to breast cancer progression. However, Ragnarsson et al. [15] concluded that FasL is expressed intracellularly in both normal and malignant breast epithelium and is unlikely to be important for the immune evasion of breast tumours.

We previously established the FasL: Fas ratio in tumour tissue as a prognostic factor in breast carcinomas [14]. An extended follow up allows a re-evaluation of our database regarding the prognostic and predictive value of FasL: Fas ratio in breast carcinomas. In particular, we investigated for the first time whether the FasL: Fas ratio may predict response to cytotoxic or hormonal therapies, in the same way that the presence of hormone receptors predicts response to hormonal treatment. Using data obtained by analysis in various subgroups, the findings presented here contribute to the recent controversial discussion on the effects of tumour-expressed FasL in vivo.

\section{Materials and method}

\section{Patients and tissue collection}

Tissue samples from 215 unselected primary breast carcinomas were collected during surgery at the Department of Obstetrics and Gynaecology of the University of Rostock between 1994 and 1998. None of the patients had received chemotherapy, radiotherapy or immunotherapy before surgery. The mean age for breast cancer patients was 58 years (range 29-90 years). The majority of breast tumours ( $n=199$ [92.5\%]) were invasive ductal carcinomas. The median follow-up time was 54 months (range 2-77 months).

The main classifying prognostic factors are shown in Table 1. A total of 200 patients (93\%) received post- operative adjuvant therapy, consisting of chemotherapy $(n=52)$, hormone therapy $(n=96)$, or both $(n=52)$. Among patients undergoing endocrine treatment 90 women (93.7\%) were treated with tamoxifen, receiving an oral dose of $20 \mathrm{mg} /$ day tamoxifen for a maximum of 5 years. Among the tamoxifen-treated group, we excluded four patients with hormone receptor negative tumours from further survival analysis. Of the remaining 86 patients, 41 blood samples were available for detection of serum oestradiol concentrations using the SR1 enzyme immunoassay (BioChem Immunosystems $\mathrm{GmbH}$, Freiburg, Germany).

\section{Real-time reverse transcription polymerase chain reaction}

The RT-PCR procedure and preparation of RNA standard were described previously $[14,16]$. In brief, total RNA of freshly frozen breast tissue was prepared in accordance with the acid guanidium thiocyanate-phenol-chloroform protocol. All specimens were tested by analysis of glyceraldehyde-3-phosphate dehydrogenase housekeeping gene expression using conventional RT-PCR. First-trimester placenta (FasL) from women undergoing legal abortions and liver mRNA (Fas) served as positive controls.

The primer pairs and probes were designed using the Primer Express ${ }^{\mathrm{TM}} 1.0$ program (PE Applied Biosystems, Foster City, CA, USA) and were obtained from Applied Biosystems GmbH (Weiterstadt, Germany). The primers yielded RT-PCR products of 82 (FasL) and 105 (Fas) nucleotides. For calibration of the FasL and Fas TaqMan ${ }^{\mathrm{TM}}$ assays, two RNA standards were generated using an in vitro T7-polymerase transcription system (RiboMAX ${ }^{\mathrm{TM}}$ Large Scale RNA Production System; Promega, Madison, WI, USA). The TaqMan ${ }^{\circledR}$ EZ RT-PCR Kit (PE Applied Biosystems) was used for RT and amplification of both targets and standards. Production of cDNA and PCR amplification were carried out in a single-tube, singleenzyme system, without addition of subsequent enzymes or buffers. All RT-PCR reactions were performed in duplicate, with a final volume of $25 \mu$ l.

\section{Statistical analysis}

Clinical, histological and biological parameters were compared using the most appropriate test from among the Spearman correlation coefficient, $\chi^{2}$ test, Mann-Whitney $U$ test and Kruskal-Wallis $\mathrm{H}$ test. Disease-free and overall survival were analyzed using the Kaplan-Meier method, and comparison of study groups was performed using the log-rank test. The Cox regression model was applied over both univariate and multivariate analyses, with the associated likelihood ratio test used for tests of trend differences. In multivariate analysis, a backward stepwise selection procedure was used. The Statistical Package for Social Science (SPSS Inc., Chicago, IL, USA) was used to conduct statistical analysis. In all tests $P<0.05$ was considered statistically significant and all were two-tailed tests. 
Table 1

\begin{tabular}{|c|c|c|c|c|c|}
\hline \multirow[b]{2}{*}{ Factor } & \multirow[b]{2}{*}{ Number of patients (\%) } & \multicolumn{2}{|c|}{ Disease-free survival } & \multicolumn{2}{|c|}{ Overall survival } \\
\hline & & $P$ & $\mathrm{RR}(95 \% \mathrm{Cl})$ & $P$ & RR (95\% Cl) \\
\hline \multicolumn{6}{|c|}{ Menopausal status $(n=209)$} \\
\hline Premenopausal & $62(29.7)$ & 0.121 & $1.73(0.86-3.47)$ & 0.061 & $2.49(0.96-6.45)$ \\
\hline Postmenopausal & $147(70.3)$ & & & & \\
\hline \multicolumn{6}{|c|}{ Histological grading $(n=206)$} \\
\hline 1 & $101(49.0)$ & 0.113 & $1.36(0.93-2.0)$ & 0.003 & $1.93(1.25-3.0)$ \\
\hline II & $81(39.3)$ & & & & \\
\hline III & $24(11.7)$ & & & & \\
\hline \multicolumn{6}{|c|}{ Lymph node status ( $n=203)$} \\
\hline Negative & $116(57.1)$ & 0.009 & $2.22(1.22-4.03)$ & 0.095 & $1.85(0.9-3.82)$ \\
\hline Positive & $88(42.9)$ & & & & \\
\hline \multicolumn{6}{|l|}{ Tumour size $(n=205)$} \\
\hline $\mathrm{pT} 1$ & $93(45.4)$ & 0.001 & $1.85(1.29-2.65)$ & $<0.001$ & $2.3(1.53-3.45)$ \\
\hline pT2 & $96(46.8)$ & & & & \\
\hline pT3 and pT4 & $16(7.8)$ & & & & \\
\hline \multicolumn{6}{|c|}{ Oestrogen receptor status $(n=208)$} \\
\hline$\leq 10 \mathrm{fmol} / \mathrm{mg}$ & $74(35.6)$ & 0.73 & $1.12(0.58-2.16)$ & 0.547 & $1.29(0.56-2.99)$ \\
\hline$>10 \mathrm{fmol} / \mathrm{mg}$ & $134(64.4)$ & & & & \\
\hline \multicolumn{6}{|c|}{ Progesterone receptor status $(n=205)$} \\
\hline$\leq 10 \mathrm{fmol} / \mathrm{mg}$ & $118(57.6)$ & 0.056 & $0.57(0.33-1.01)$ & 0.636 & $0.84(0.42-1.67)$ \\
\hline$>10 \mathrm{fmol} / \mathrm{mg}$ & $87(42.4)$ & & & & \\
\hline \multicolumn{6}{|c|}{ Fas ligand: Fas ratio $(n=211)$} \\
\hline$\leq 1$ & 139 & 0.023 & $1.92(1.09-3.35)$ & 0.172 & $1.61(0.81-3.2)$ \\
\hline$>1$ & 72 & & & & \\
\hline
\end{tabular}

$\mathrm{Cl}$, confidence interval; $\mathrm{RR}$, relative risk.

\section{Results}

\section{Analysis of survival among the total study group}

The impact of established prognostic parameters regarding disease-free and overall survival for the total population is listed in Table 1. Tumour size $(P=0.001)$ and lymph node status $(P=0.009)$ were significant factors for disease-free survival, whereas tumour size $(P<0.001)$ and histological grading $(P=0.003)$ were significant prognostic parameters for overall survival within univariate analysis.

Using the cutoff value of 1, a FasL : Fas ratio greater than 1 was found to be a significant prognostic factor for disease-free survival in the present update analysis. It was associated with a significantly decreased disease-free survival $(P=0.022$; Fig. 1a) and with a tendency toward increased mortality $(P=0.14$; Fig. $1 \mathrm{~b})$. The mean diseasefree survival time for patients with a ratio of 1 or less was 67 months (95\% confidence interval [Cl] 63-70 months) versus 59 months (95\% Cl 53-65 months) for patients with a ratio greater than 1 .

All variables that achieved significance in the univariate survival analysis were incorporated in a multivariate analysis (Table 2). Tumour size $(P=0.004)$ and lymph node status $(P=0.04)$ were of independent significance in the multivariate disease-free survival analysis $(n=208)$. Furthermore, tumour size $(P=0.001)$ and grading $(P=0.023)$ were independent prognostic parameters for overall survival in the multivariate model $(n=208)$.

\section{Analysis of survival among tamoxifen-treated patients}

Ideally, a predictive factor should be evaluated only in the setting of individuals who have not received different systemic therapies. For this reason we divided the total population into hormone receptor positive tamoxifen-treated $(n=86)$ and chemotherapy-treated $(n=52)$ subgroups. Among the tamoxifen-treated subgroup 75 patients $(83.3 \%)$ were node negative. The FasL:Fas ratio values were positively correlated with histological grading $(P=0.048)$ and serum oestradiol concentrations $(P=0.04)$. Women with a FasL: Fas ratio greater than 1 had significantly higher serum oestradiol levels than did women with a FasL: Fas ratio of 1 or less $(P=0.002)$. No associations between FasL: Fas ratio and other factors such as tumour size $(P=0.129)$, lymph node status $(P=0.378)$, age $(P=0.822)$, body mass index $(P=0.174)$ and use of exogenous hormones $(P=0.732)$ were observed. 
Figure 1

(a)

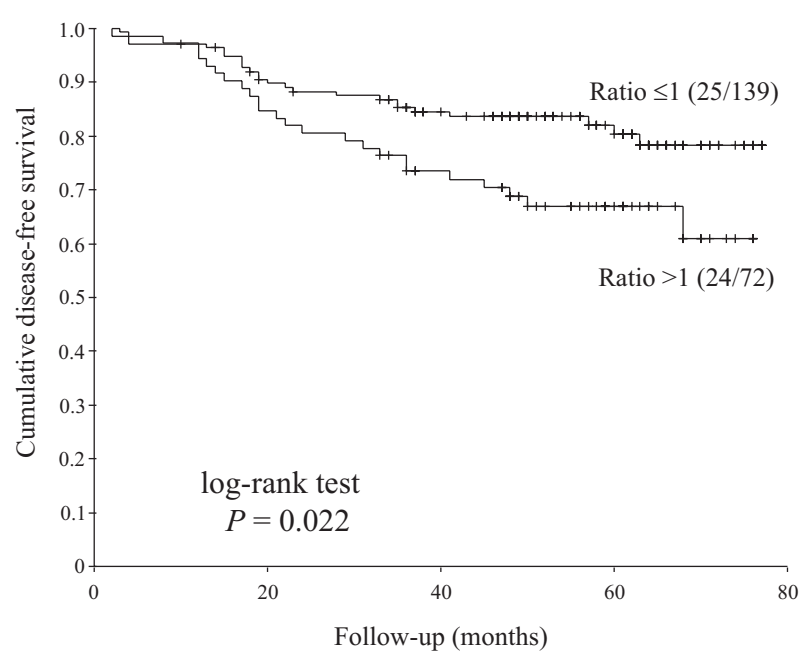

(b)

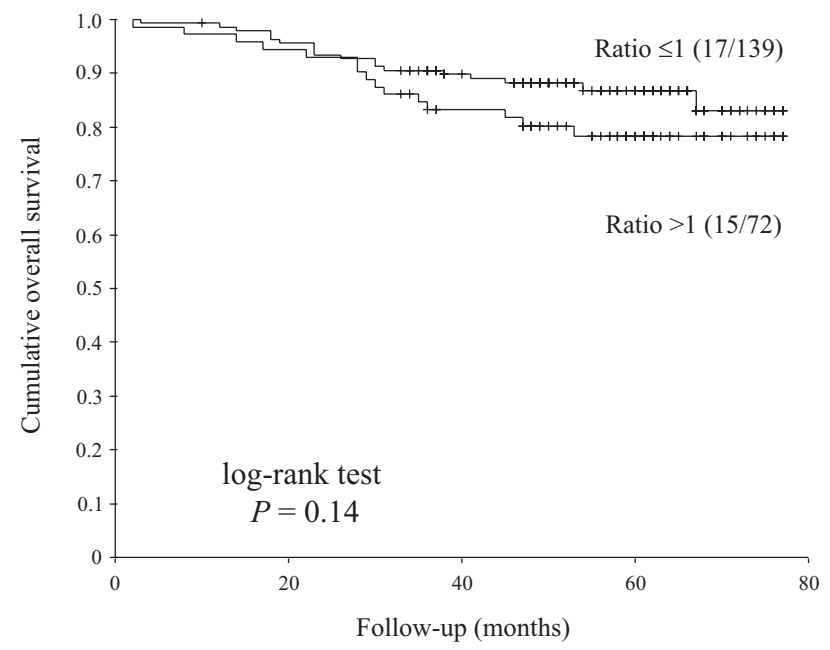

(a) Disease-free and (b) overall survival curves for breast cancer patients $(n=211)$ with respect to Fas ligand (FasL) : Fas ratio. Survival was analyzed using the Kaplan-Meier method, and comparison of study groups was performed using the log-rank test.

Table 2

Multivariate Cox regression analysis for disease-free and overall survival, including prognostic factors that were significant on univariate analysis

\begin{tabular}{lccccc}
\hline & \multicolumn{2}{c}{ Disease-free survival } & & & Overall survival \\
\cline { 2 - 5 } \cline { 5 - 6 } Variable & $P$ & $\mathrm{RR}(95 \% \mathrm{Cl})$ & & $P$ & $\mathrm{RR}(95 \% \mathrm{Cl})$ \\
\hline Histological grading & - & - & 0.023 & $1.68(1.07-2.62)$ \\
Lymph node status & 0.04 & $1.9(1.03-3.49)$ & & - & - \\
Tumour size & 0.004 & $1.77(1.2-2.6)$ & & 0.001 & $2.1(1.38-3.2)$ \\
Fas ligand: Fas ratio & 0.161 & $1.52(0.85-2.73)$ & & - & - \\
\hline
\end{tabular}

The analysis was conducted in 208 women. $\mathrm{Cl}$, confidence interval; RR, relative risk.

Women exclusively treated with tamoxifen $(n=86)$ and with a FasL:Fas ratio greater than 1 had a significantly decreased disease-free survival $(P=0.0084)$ and overall survival $(P=0.03)$ on univariate Kaplan-Meier analysis (Fig. 2). The mean disease-free survival time for tamoxifentreated patients with a ratio of 1 or less was 71 months (95\% Cl 67-75 months) versus 57 months $(95 \% \mathrm{Cl}$ 48-67 months) for patients with a ratio greater than 1 . The corresponding data for overall survival were 74 months (95\% Cl 70-77 months) for a ratio of 1 or less and 66 months (95\% Cl 58-73 months) for a ratio greater than 1. Tumour size $(P=0.013)$ and FasL: Fas ratio $(P=0.013)$ were significantly related to reduced diseasefree survival in univariate Cox regression analysis (Table 3). Tumour size $(P=0.023)$ and FasL: Fas ratio $(P=0.027)$ were also of independent prognostic significance in the multivariate model $(n=86)$. The relative risk for occurrence of breast cancer related relapse in tamox- ifen-treated patients was 3.0 (95\% Cl 1.14-7.9) for women with a FasL: Fas ratio greater than 1.

Corresponding analyses for overall survival in tamoxifentreated patients revealed prognostic impact of tumour size $(P=0.002)$, tumour grading $(P=0.015)$ and FasL: Fas ratio $(P=0.042)$ in the univariate setting. The multivariate analysis confirmed all three of those parameters as independent markers for overall survival in tamoxifen-treated patients (Table 3 ).

\section{Analysis of survival among postmenopausal patients} The tamoxifen-treated subgroup (age range 50-90 years) comprised $94.5 \%$ postmenopausal and $5.5 \%$ premenopausal patients, and we therefore re-analyzed the data for the postmenopausal population $(n=149)$. On univariate Kaplan-Meier analysis, postmenopausal women with a FasL:Fas ratio greater than 1 had decreased 
(a)

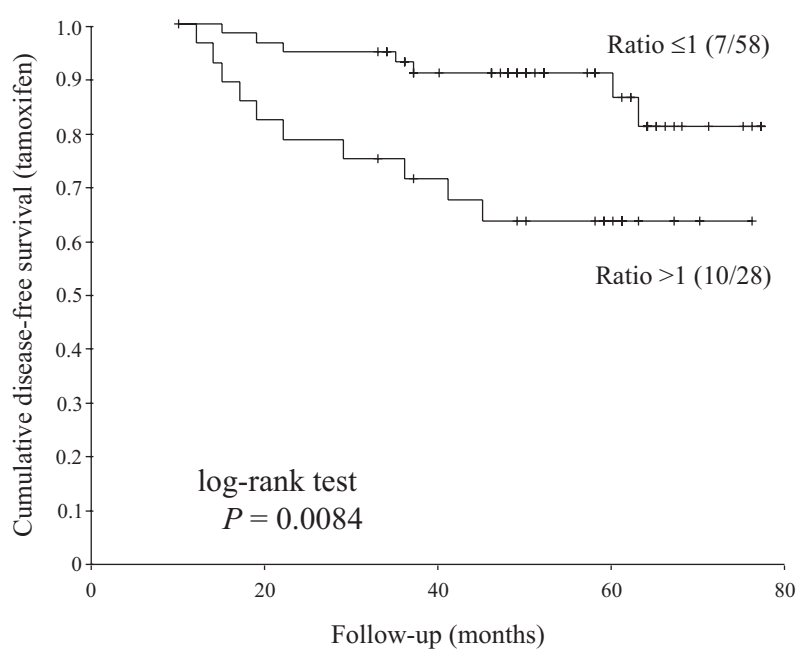

(b)

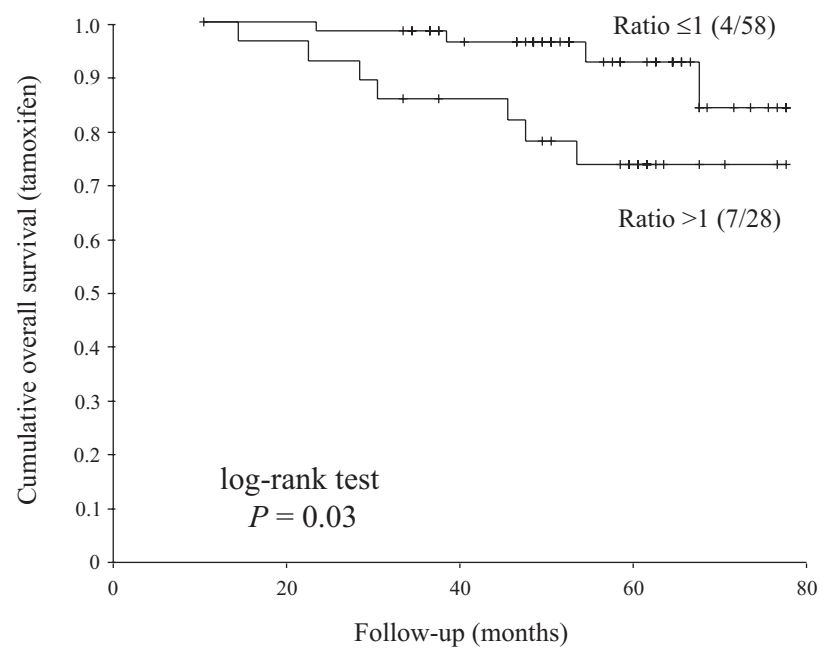

(a) Disease-free and (b) overall survival curves for tamoxifen-treated, hormone receptor positive breast cancer patients ( $n=86$ ) with respect to Fas ligand (FasL) : Fas ratio. Survival was analyzed using the Kaplan-Meier method, and comparison of study groups was performed using the log-rank test.

Table 3

Cox regression analysis for disease-free and overall survival in tamoxifen-treated, hormone receptor positive patients

\begin{tabular}{|c|c|c|c|c|c|c|c|c|}
\hline \multirow[b]{3}{*}{ Variable } & \multicolumn{4}{|c|}{ Disease-free survival analysis } & \multicolumn{4}{|c|}{ Overall survival analysis } \\
\hline & \multicolumn{2}{|c|}{ Univariate } & \multicolumn{2}{|c|}{ Multivariate } & \multicolumn{2}{|c|}{ Univariate } & \multicolumn{2}{|c|}{ Multivariate } \\
\hline & $P$ & $\mathrm{RR}(95 \% \mathrm{Cl})$ & $P$ & $\mathrm{RR}(95 \% \mathrm{Cl})$ & $P$ & $\mathrm{RR}(95 \% \mathrm{Cl})$ & $P$ & $\mathrm{RR}(95 \% \mathrm{Cl})$ \\
\hline Grading & 0.151 & $1.7(0.82-3.16)$ & - & - & 0.015 & $2.81(1.22-6.5)$ & 0.025 & $2.69(1.13-6.4)$ \\
\hline Lymph node status & 0.284 & $1.89(0.59-6.03)$ & - & - & 0.055 & $3.81(1.02-14.3)$ & - & - \\
\hline Tumour size & 0.013 & $2.25(1.18-4.26)$ & 0.023 & $2.24(1.12-4.5)$ & 0.002 & $3.43(1.56-7.56)$ & 0.005 & $3.83(1.51-9.72)$ \\
\hline FasL : Fas ratio & 0.013 & $3.4(1.29-8.96)$ & 0.027 & $3.0(1.14-7.9)$ & 0.042 & $3.59(1.05-12.3)$ & 0.043 & $3.65(1.04-12.8)$ \\
\hline
\end{tabular}

The analysis was conducted in 86 women. $\mathrm{Cl}$, confidence interval; FasL, Fas ligand; RR, relative risk.

disease-free survival $(P=0.01)$ and overall survival $(P=0.182)$ as compared with postmenopausal women with a ratio of 1 or less (Fig. 3). The mean disease-free survival time for postmenopausal patients with a ratio of 1 or less was 67 months (95\% Cl 62-71 months) versus 56 months (95\% Cl 49-63 months) for patients with a ratio greater than 1 . The corresponding data for overall survival were 69 months (95\% Cl 65-73 months) and 65 months (95\% Cl 59-71 months), respectively. Tumour size $(P=0.001)$ and FasL: Fas ratio $(P=0.01)$ were significantly related to reduced disease-free survival on univariate Cox regression analysis (Table 4).

Both factors (tumour size $P=0.003$; FasL: Fas ratio $P=0.028)$ retained independent prognostic significance in the multivariate model $(n=148)$. The relative risk for occurrence of breast cancer related relapse in post- menopausal patients was 2.04 (95\% Cl 1.14-7.36) for women with a ratio greater than 1. Among the postmenopausal subgroup no associations between FasL: Fas ratio and other factors such as tumour size $(P=0.096)$, tumour grading $(P=0.108)$, lymph node status $(P=0.339)$, age $(P=0.55)$, oestrogen receptor (ER; $P=0.741)$, progesterone receptor $(P=0.748)$, body mass index $(P=0.92)$ and use of exogenous hormones $(P=0.26)$ were observed.

\section{Analysis of survival among patients undergoing cytotoxic therapy}

In contrast to the findings summarized above, FasL: Fas ratio had no significant prognostic value in patients treated exclusively with chemotherapy. Using Kaplan-Meier analysis, disease-free $(P=0.94)$ and overall survival $(P=0.765)$ were not related to FasL: Fas ratio. Similarly, 
Figure 3

(a)

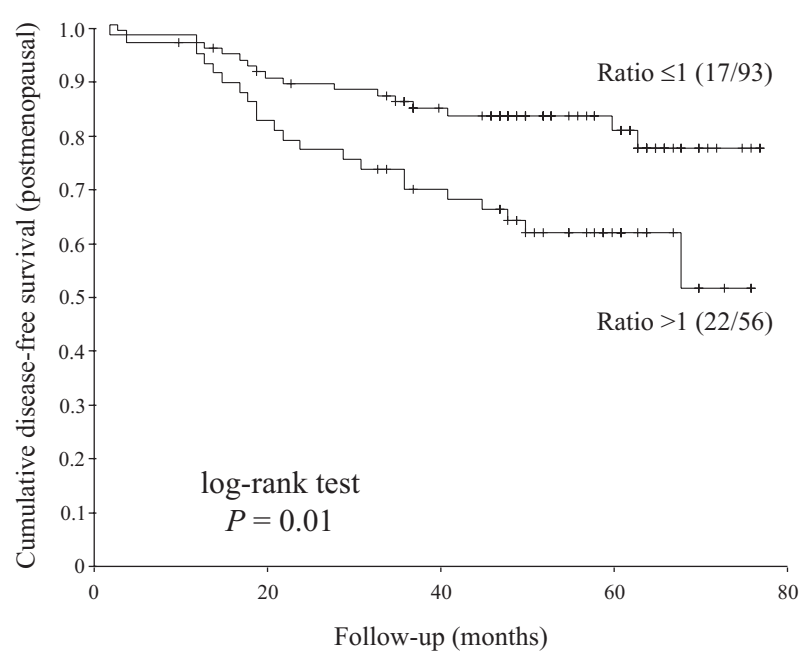

(b)

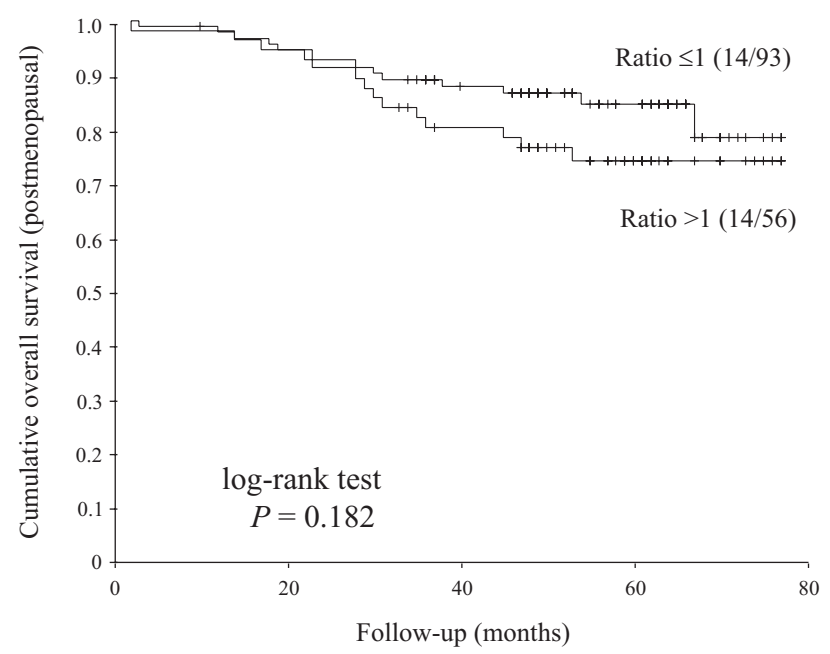

(a) Disease-free and (b) overall survival curves for postmenopausal breast cancer patients $(n=149)$ with respect to Fas ligand (FasL) : Fas ratio. Survival was analyzed using the Kaplan-Meier method, and comparison of study groups was performed using the log-rank test.

Table 4

Cox regression analysis for disease-free and overall survival in postmenopausal patients

\begin{tabular}{|c|c|c|c|c|c|c|c|c|}
\hline \multirow[b]{3}{*}{ Variable } & \multicolumn{4}{|c|}{ Disease-free survival analysis } & \multicolumn{4}{|c|}{ Overall survival analysis } \\
\hline & \multicolumn{2}{|c|}{ Univariate } & \multicolumn{2}{|c|}{ Multivariate } & \multicolumn{2}{|c|}{ Univariate } & \multicolumn{2}{|c|}{ Multivariate } \\
\hline & $P$ & $\mathrm{RR}(95 \% \mathrm{Cl})$ & $P$ & $\mathrm{RR}(95 \% \mathrm{Cl})$ & $P$ & $\mathrm{RR}(95 \% \mathrm{Cl})$ & $P$ & $\mathrm{RR}(95 \% \mathrm{Cl})$ \\
\hline Grading & 0.107 & $1.42(0.93-2.17)$ & - & - & 0.015 & $1.81(1.12-2.91)$ & 0.059 & $1.58(0.98-2.56)$ \\
\hline Lymph node status & 0.05 & $1.97(1.01-3.87)$ & - & - & 0.134 & $1.83(0.83-4.05)$ & - & - \\
\hline Tumour size & 0.001 & $1.85(1.27-2.7)$ & 0.003 & $1.79(1.22-2.64)$ & 0.001 & $2.11(1.38-3.23)$ & 0.002 & $1.97(1.27-3.03)$ \\
\hline ER status & 0.774 & $1.12(0.53-2.34)$ & - & - & 0.903 & $0.95(0.4-2.24)$ & - & - \\
\hline PgR status & 0.19 & $0.65(0.34-1.23)$ & - & - & 0.558 & $0.8(0.37-1.7)$ & - & - \\
\hline FasL : Fas ratio & 0.01 & $2.29(1.22-4.32)$ & 0.028 & $2.04(1.08-3.85)$ & 0.187 & $1.65(0.78-3.46)$ & - & - \\
\hline
\end{tabular}

The analysis was conducted in 148 women. $\mathrm{Cl}$, confidence interval; ER, oestrogen receptor; FasL, Fas ligand; PgR, progesterone receptor; RR, relative risk.

no significant associations were found between FasL: Fas ratio and survival time in premenopausal patients (data not shown).

\section{Recurrence pattern}

Because of the significance of FasL: Fas ratio for diseasefree survival in postmenopausal or tamoxifen-treated women, we analyzed the pattern of locoregional and distant relapse. Among the 149 postmenopausal patients, 39 $(26.2 \%)$ had recurrent disease. The relapse rate was $39.3 \%(n=22)$ in 56 patients with a ratio greater than 1 and $18.3 \%(n=17)$ in 93 women with a ratio of 1 or less. Skeletal (41.2\%) and pulmonary metastases (23.5\%), and locoregional progression (23.5\%) were frequently observed in postmenopausal patients with a ratio of 1 or less. Liver (33.3\%) and skeletal metastases (22.2\%), and locoregional progression (22.2\%) occurred predominantly in patients with a ratio greater than 1 . However, no specific recurrence patterns were detected with respect to FasL: Fas ratio.

\section{Discussion}

At present there are only two factors with clinical level 1 evidence supporting a predictive role for response to breast cancer therapy. First, optimal adjuvant hormonal therapy is 5 years of tamoxifen for anyone with a tumour that is hormone receptor positive, even if at a low level. 
Patients whose cancers express neither ER nor progesterone receptor will not be helped by tamoxifen administration [17]. Second, recent data suggest that adjuvant treatment with trastuzumab will prove ineffective for tumours with low levels of HER-2/neu expression [18].

The new data presented here indicate that the FasL: Fas ratio may be useful not only as a prognostic factor but also as a predictive factor for projecting response to the antioestrogen tamoxifen. In patients with hormone receptor positive primary tumours, a FasL: Fas ratio greater than 1 defines a subgroup of patients who are less likely to respond to tamoxifen. Women exclusively treated with tamoxifen and with a FasL: Fas ratio greater than 1 had a 14-month shorter mean disease-free survival and a relative risk of 3.0 for relapse of disease as compared with patients with a FasL : Fas ratio of 1 or less. Furthermore, a ratio greater than 1 was associated with a significantly shorter overall survival $(P=0.043)$ and a relative risk for death of 3.65 in that subgroup. No correlation was seen between FasL:Fas ratio and survival time in patients receiving cytotoxic treatment.

The unexpected finding that FasL: Fas ratio is a prognostic factor in postmenopausal and a predictive factor in tamoxifen-treated patients may be accounted for by hormone dependency. Various studies suggest that the FasL/Fas system may play an important role in the regulation of cell death in response to hormonal changes. Nilsen et al. [19] showed that oestrogen induces apoptosis in neurone-like cells that express ER- $\beta$, and that this is mediated by the FasL/Fas system. Selam et al. [20] suggested that oestradiol and progesterone may play a role in regulating maternal immunotolerance for the implantation of a semiallograft embryo by inducing FasL expression in human endometrium. Recent findings support the hypothesis that oestrogen-induced thymic atrophy occurs as a result of apoptosis and is mediated by oestrogen-induced FasL expression [21]. Finally, maintenance of endothelial FasL expression by oestradiol may represent a mechanism for the apparently antiatherogenic effect of oestrogen [22].

Novel findings further link the FasL/Fas system and hormones such as oestrogen and lactogenic hormones to the biology of the normal mammary gland and the development of breast cancer [23]. Treatment of LTED cells, which were derived by growing MCF-7 breast cancer cells under long-term oestrogen-deprived conditions, with oestradiol increased the expression of FasL [24]. Mor et al. [25] showed that FasL in breast tissue is functionally active, and that oestrogen and tamoxifen regulate its expression. Those investigators identified an oestrogenrecognizing element-like motif in the promoter region of the FasL gene, suggesting direct effects of oestrogen on FasL expression. This effect is receptor mediated because tamoxifen blocked the oestrogenic effect.
The indication for use of antioestrogens in mammary carcinoma arises from the observations that oestrogen is a mitogen in breast cancer and that approximately one-third of patients will respond to endocrine therapy. The main therapeutic antioestrogen that has been used is tamoxifen. The present data indicate that the antitumour effect of tamoxifen varies according to the FasL:Fas ratio of the breast tumour, and values of the ratio are positively correlated to serum oestradiol levels. The use of tamoxifen in patients with a FasL: Fas ratio greater than 1 is less effective than in those with higher ratios, leading to the hypothesis that the recently developed aromatase inhibitors anastrozole, letrozole and exemestan are more appropriate in these patients, or that additional cytotoxic treatment will be of benefit in this subgroup.

The role of FasL expressed by breast tumour in the induction of apoptosis of infiltrating Fas-expressing immune cells, and thereby conferring immune privilege on the tumour, is at present unclear $[8,10]$. The expression of FasL by tumours implies not only that cancers have acquired defensive strategies (Fas resistance) but also that they can take the offensive (counterattack) $[26,27]$. On the basis of the findings presented here, we hypothesize that the association between high-FasL/low-Fas phenotype and shorter disease-free survival in older breast carcinoma patients may be due to a decline in immune function, which results in increased escape of tumour cells from immune surveillance.

Of special interest are age-related changes in tumourinfiltrating lymphocytes. Cytotoxic lymphocytes from aged mice are less able to bind targets, although they appear to be equally effective in destroying their targets [28]. Assuming that FasL-positive tumour cells interact with tumour-infiltrating lymphocytes, our clinical data support indirectly the counterattack model. Immune surveillance among older patients is insufficient in breast carcinomas with a FasL: Fas ratio greater than 1, which leads to an increased rate of locoregional or distant metastases and to a shorter disease-free survival in postmenopausal patients. However, there is little evidence to support direct causal links between immune senescence and most malignancies, although data from in vitro and in vivo animal and human studies demonstrate clear age-related alterations in both cellular and humoral components of the immune system [29].

\section{Conclusion}

The present findings confirm the prognostic significance of FasL: Fas ratio in breast carcinoma in a re-evaluated database over 54 months of follow up. Particularly in postmenopausal patients, the FasL:Fas ratio retained independent prognostic significance in multivariate analysis for disease-free survival. Additionally, the data strongly support a correlation between FasL: Fas ratio greater than 
1 and lack of efficacy of tamoxifen in hormone receptor positive patients. However, given the important therapeutic repercussions of this issue, further studies are required before evaluation of FasL: Fas ratio can be routinely used to select patients who are likely to benefit from tamoxifen administration.

\section{Acknowledgements}

Supported by the Deutsche Forschungsgemeinschaft (RE 1467/3-1) and the University of Rostock (FORUN 989011).

\section{References}

1. Walczak H, Krammer PH: The CD95 (APO-1/Fas) and the TRAIL (APO-2L) apoptosis sytems. Exp Cell Res 2000, 256:5866.

2. Nagata S, Golstein P: The Fas death receptor. Science 1995, 267:1449-1456.

3. Hahne M, Rimoldi D, Schröter M, Romero P, Schreier M, French LE, Schneider P, Bornand T, Fontana A, Lienard D, Cerottini J, Tschopp J: Melamoma cell expression of Fas (Apo-1/CD95) ligand: implications for tumor immune escape. Science 1996, 274:1363-1366.

4. O'Connell J, O'Sullivan GC, Collins JK, Shanahan F: The Fas counterattack: Fas-mediated $\mathrm{T}$ cell killing by colon cancer cells expressing Fas ligand. J Exp Med 1996, 184:1075-1082.

5. Chappell DB, Zaks TZ, Rosenberg SA, Restifo NP: Human melanoma cells do not express Fas (Apo-1/CD95) ligand. Cancer Res 1999, 59:59-62.

6. Favre-Felix N, Fromentin A, Hammann A, Solary E, Martin F, Bonnotte B: The tumor counterattack hypothesis revisited: colon cancer cells do not induce T cell apoptosis via the Fas (CD95, APO-1) pathway. J Immunol 2000, 164:5023-5027.

7. Arai H, Gordon D, Nabel EG, Nabel GJ: Gene transfer of Fas ligand induces tumor regression in vivo. Proc Natl Acad Sci USA 1997, 94:13862-13867.

8. O'Connell J, Houston A, Bennett MW, O'Sullivan GC, Shanahan $\mathrm{F}$ : Immune privilege or inflammation? Insights into the Fas ligand enigma. Nat Med 2001, 7:271-274.

9. Restifo NP: Not so Fas: re-evaluating the mechanisms of immune privilege and tumor escape. Nat Med 2000, 6:493495.

10. Restifo NP: Countering the 'counterattack' hypothesis. Nat Med 2001, 7:259.

11. Herrnring C, Reimer T, Jeschke U, Makovitzky J, Krüger K, Gerber B, Kabelitz D, Friese K: Expression of the apoptosis-inducing ligands FasL and TRAIL in malignant and benign breast tumors. Histochem Cell Biol 2000, 113:189-194.

12. Mottolese M, Buglioni S, Bracalenti $C$, Cardarelli MA, Ciabocco L, Giannarelli D, Botti C, Natali PG, Concetti A, Venanzi FM: Prognostic relevance of altered Fas (CD95)-system in human breast cancer. Int J Cancer 2000, 89:127-132.

13. Müschen M, Moers $C$, Warskulat U, Niederacher D, Betz B, Even J, Lim A, Josien R, Beckmann MW, Häussinger D: CD95 ligand expression in dedifferentiated breast cancer. J Pathol 1999, 189:378-386.

14. Reimer T, Herrnring C, Koczan D, Richter D, Gerber B, Kabelitz D, Friese K, Thiesen HJ: FasL:Fas ratio: a prognostic factor in breast carcinomas. Cancer Res 2000, 60:822-828.

15. Ragnarsson GB, Mikaelsdottir EK, Vidarsson H, Jònasson JG, Òlafsdòttir K, Kristjànsdòttir K, Kjartansson J, Ögmundsdòttir HM, Rafnar T: Intracellular Fas ligand in normal and malignant breast epithelium does not induce apoptosis in Fas-sensitive cells. Br J Cancer 2000, 83:1715-1721.

16. Reimer T, Koczan D, Briese V, Friese K, Richter D, Thiesen HJ, Jeschke U: Absolute quantification of human chorionic gonadotropin- $\beta$ mRNA with TaqMan ${ }^{\mathrm{TM}}$ detection. Mol Biotechnol 2000, 14:47-57.

17. Early Breast Cancer Trialists' Collaborative Group: Tamoxifen for early breast cancer: an overview of the randomized trials. Lancet 1998, 351:1451-1467.

18. Cobleigh MA, Vogel CL, Tripathy D, Robert NJ, Scholl S, Fehrenbacher L, Wolter JM, Paton V, Shak S, Lieberman G, Slamon DJ: Multinational study of the efficacy and safety of humanized anti-HER2 monoclonal antibody in women who have HER2- overexpressing metastatic breast cancer that has progressed after chemotherapy for metastatic disease. J Clin Oncol 1999, 17:2639-2648.

19. Nilsen J, Mor G, Naftolin F: Estrogen-regulated developmental neuronal apoptosis is determined by estrogen receptor subtype and the Fas/Fas ligand system. J Neurobio/ 2000, 43: 64-78.

20. Selam B, Kayisli UA, Mulayim N, Arici A: Regulation of Fas ligand expression by estradiol and progesterone in human endometrium. Biol Reprod 2001, 65:979-985.

21. Mor G, Munoz A, Redlinger R, Silva I, Song J, Lim C, Kohen F: The role of the Fas/Fas ligand system in estrogen-induced thymic alteration. Am J Reprod Biol 2001, 46:298-307.

22. Amant $\mathrm{C}$, Holm P, Xu S, Tritman N, Kearney M, Losordo DW: Estrogen receptor-mediated, nitric oxide-dependent modulation of immunologic barrier function of the endothelium: regulation of Fas ligand by estradiol. Circulation 2001, 104: 2576-2581.

23. Song J, Sapi E, Brown W, Nilsen J, Tartaro K, Kacinski BM, Craft J, Naftolin F, Mor G: Roles of Fas and Fas ligand during mammary gland remodeling. J Clin Invest 2000, 106:12091220.

24. Song RXD, Mor G, Naftolin F, McPherson RA, Song J, Zhang Z, Yue W, Wang J, Santen RJ: Effect of long-term estrogen deprivation on apoptotic responses of breast cancer cells to $17 \beta$ estradiol. J Natl Cancer Inst 2001, 93:1714-1723.

25. Mor G, Kohen F, Garcia-Velasco J, Nilsen J, Brown W, Song J, Naftolin F: Regulation of Fas ligand expression in breast cancer cells by estrogen: functional differences between estradiol and tamoxifen. J Steroid Biochem Mol Biol 2000, 73: 185-194.

26. O'Connell J, Bennett MW, O'Sullivan GC, O'Callaghan J, Collins JK, Shanahan F: Expression of Fas (CD95/APO-1) ligand by human breast cancers: significance for tumor immune privilege. Clin Diagn Lab Immunol 1999, 6:457-463.

27. O'Connell J, Bennett MW, O'Sullivan GC, Collins JK, Shanahan F: The Fas counterattack: cancer as a site of immune privilege. Immunol Today 1999, 20:46-52.

28. Gottesman SRS, Edington J: Proliferative and cytotoxic immune functions in aging mice. V. Deficiency in generation of cytotoxic cells with normal lytic function per cell as demonstrated by the single cell conjugation assay. Aging Immunol Infect Dis 1990, 2:19-29.

29. Burns EA, Leventhal EA: Aging, immunity, and cancer. Cancer Control 2000, 7:513-522. 